\title{
Corrigendum
}

\section{Corrigendum to "Fractal Model for Acoustic Absorbing of Porous Fibrous Metal Materials"}

\author{
Weihua Chen, ${ }^{1,2}$ Tianning Chen, ${ }^{1}$ Xiaopeng Wang, ${ }^{1}$ Jiuhui Wu, ${ }^{1}$ and Suobin $\mathrm{Li}^{1}$ \\ ${ }^{1}$ School of Mechanical Engineering and State Key Laboratory for Strength and Vibration of Mechanical Structures, \\ Xian Jiaotong University, Xian, Shaanxi 710049, China \\ ${ }^{2}$ College of Mechano-Electronic Engineering, Lanzhou University of Technology, Lanzhou 730050, China
}

Correspondence should be addressed to Xiaopeng Wang; xpwang@mail.xjtu.edu.cn

Received 29 March 2017; Accepted 5 April 2017; Published 11 May 2017

Copyright (C) 2017 Weihua Chen et al. This is an open access article distributed under the Creative Commons Attribution License, which permits unrestricted use, distribution, and reproduction in any medium, provided the original work is properly cited.

In the article titled "Fractal Model for Acoustic Absorbing of Porous Fibrous Metal Materials" [1], Figure 12(b) in Section 4.1 ("Experiment and Verification of $\sigma$ ") is blanked since it is an in-house apparatus of the Institute of Acoustics at the Chinese Academy of Sciences and was published without their permission. In addition, the statement "The inner diameter of the measuring tube is greater than $95 \mathrm{~mm}$ and the minimum air velocity can reach $0.5 \times 10^{-3} \mathrm{~m} / \mathrm{s}$ " should be corrected to "The inner diameter of the measuring tube is $29 \mathrm{~mm}$ and the minimum air velocity can reach $0.5 \times$ $10^{-3} \mathrm{~m} / \mathrm{s} . "$

Furthermore, an acknowledgment should be added as follows.

\section{Acknowledgments}

The authors would like to thank the Institute of Acoustics at the Chinese Academy of Sciences for providing an apparatus that was used in all the measurement data of resistivity.

\section{References}

[1] W. Chen, T. Chen, X. Wang, J. Wu, and S. Li, "Fractal model for acoustic absorbing of porous fibrous metal materials," Shock and Vibration, vol. 2016, Article ID 2890857, 17 pages, 2016. 


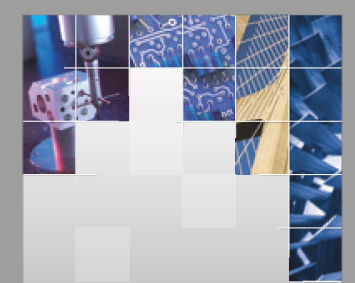

\section{Enfincering}
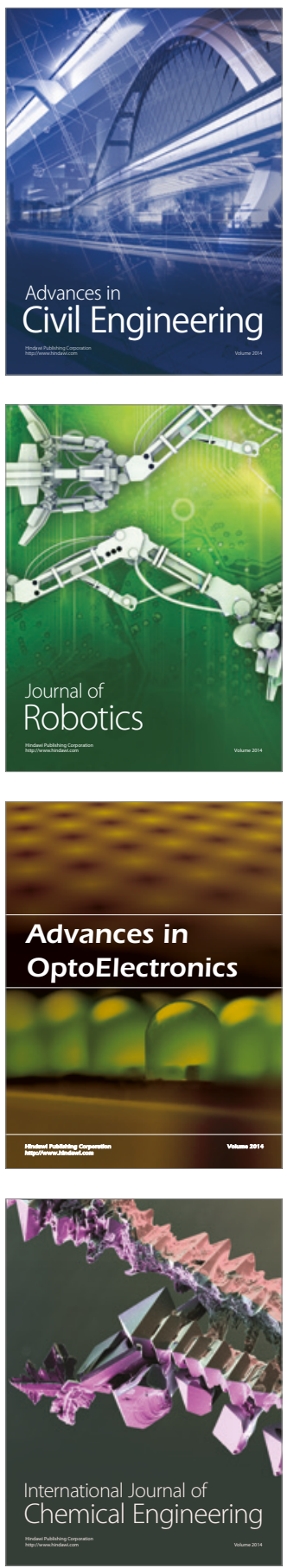

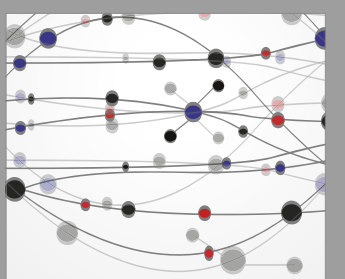

The Scientific World Journal

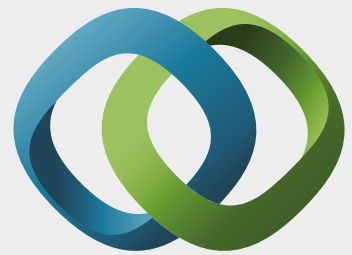

\section{Hindawi}

Submit your manuscripts at

https://www.hindawi.com
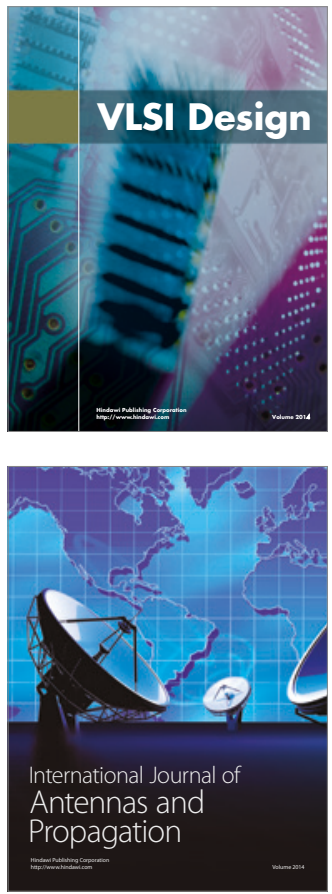

\section{Rotating}

Machinery
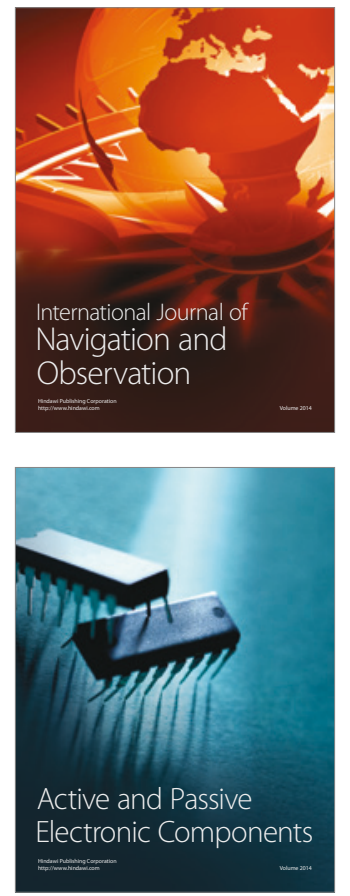
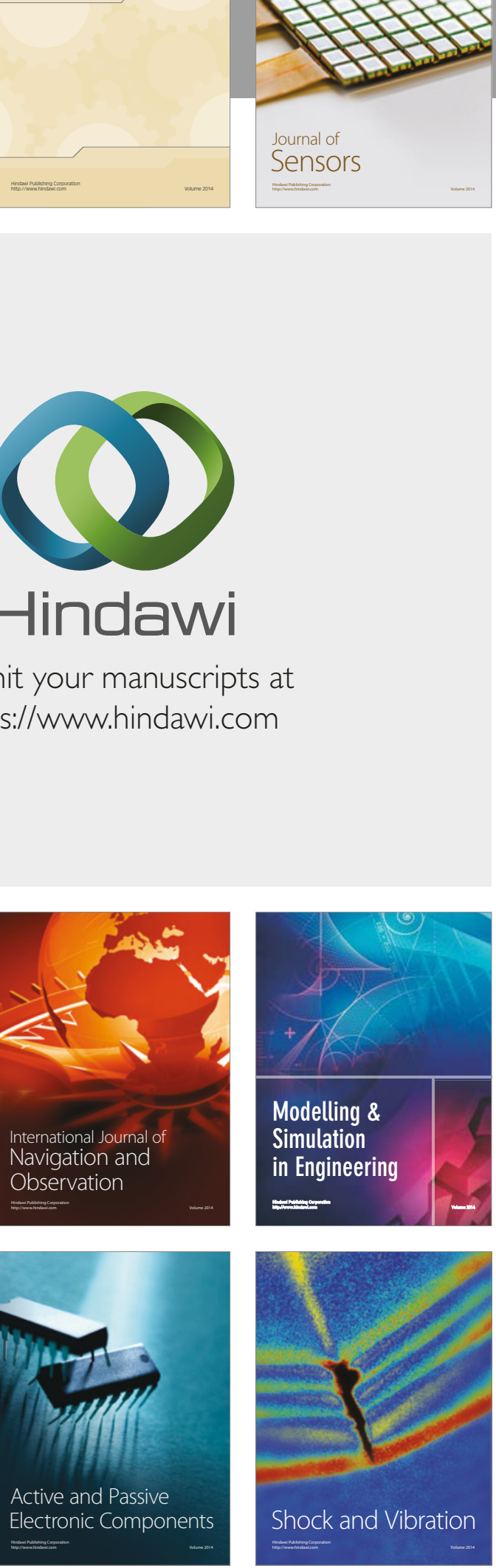
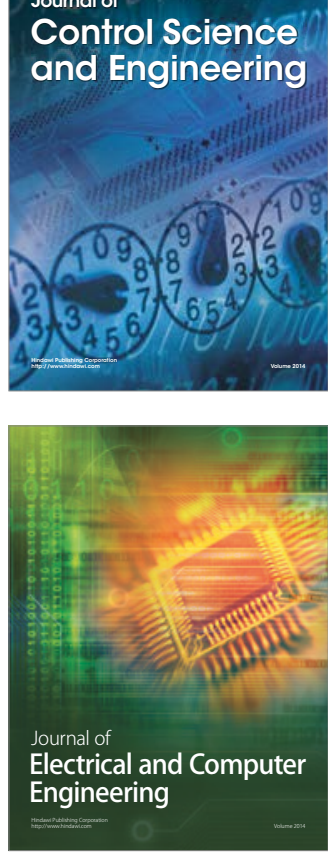

Distributed

Journal of

Control Science

and Engineering
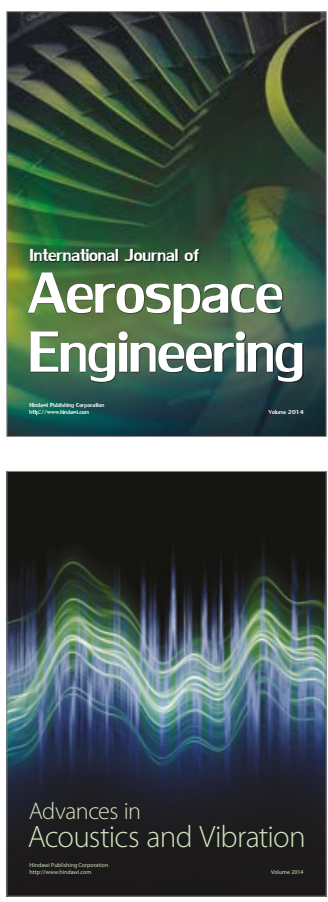

Sensor Networks 